with 20\% FBS. In some experiments, cells were treated with TNF- $\alpha(10 \mathrm{ng} / \mathrm{ml})$ and exposed to ACTZ $(500 \mathrm{mM})$ or media buffered to $\mathrm{pH}$ 6.8. In other experiments, baseline differences between PASMC proliferation from 3 experimental groups (control, Sugen/Hypoxia or Sugen/Hypoxia+ACTZ animals) were compared. Cell numbers were evaluated with a haemochromocytometer using trypan blue cell exclusion 1, 2 and 3 after stimulation in triplicates. RT-qPCR was conducted to determine the expression of proliferative, contractile and dedifferentiation markers.

Results RPASMCs exposed to TNF- $\alpha$ for 24 hours showed significant downregulation of markers of a contractile phenotype and upregulation of proliferative and de-differentiation markers. Exposure to TNF- $\alpha$ also resulted in increased proliferation, which was significantly reduced by exposure to ACTZ or acidosis. ACTZ or acidosis treatment also restored mRNA levels of contractile markers. Additionally, PASMCs isolated from control, $\mathrm{SU} / \mathrm{Hx}$ and ACTZ-treated animals retained their respective phenotypes in vitro across a panel of markers. Subsequent to stimulation with 20\% FBS, PASMCs of SU/Hx rats underwent significantly higher rates of proliferation, while cells from ACTZ-treated rats proliferated similarly to controls.

Conclusion Acetazolamide partially restores RPASMC phenotypic switching and it may do so through induction of extracellular acidosis.

\section{G567(P) EXPLORING PAEDIATRIC TRAINEES' EXPERIENCE AND TRAINING IN NEONATAL AIRWAY MANAGEMENT SKILLS}

${ }^{1} \mathrm{~K}$ Belkhatir, ${ }^{1} \mathrm{~A}$ Scrivens, ${ }^{2} \mathrm{~J}$ O'Shea, ${ }^{1} \mathrm{C}$ Roehr. ${ }^{1}$ Newborn Services, Oxford University Hospitals, Oxford, UK; ${ }^{2}$ Department of Paediatrics, Royal Hospital for Children Glasgow, Glasgow, UK

\subsection{6/archdischild-2020-rcpch.485}

Background Effective and timely airway management is crucial to successful neonatal resuscitation. Successful airway management requires training and maintaining ongoing experience, as well as a unique set of skills and equipment appropriate for the neonatal population. Level 1 trainees are required by the Royal College of Paediatrics and Child Health (RCPCH) to undertake 'advanced airway support, including tracheal intubations'. However, trends towards non-invasive respiratory support, fewer opportunities to practice at the workplace and lack of training have hindered the acquisition of these important procedural skills.

Aims To understand the experience and training of paediatric junior doctors and Advanced Neonatal Nurse Practitioners (ANNPs) in neonatal airway management skills, with a particular focus on neonatal intubation, use of videolaryngoscopy and laryngeal mask airways (LMA).

Methods An online survey was sent to trainee paediatricians and ANNPs in the UK and Ireland via deanery tutors, trainee representatives and the British Association of Perinatal Medicine (BAPM). Respondents reported their experience and training in neonatal intubation and LMA use.

Results The survey received 705 responses. Of these, 196 were junior trainees (ST1-3), 404 were senior trainees (ST48), 74 were ANNPs, 31 were clinical fellows. Experience levels were reported as: $42(6 \%)$ no experience of intubation,
$291(41 \%)<5$ term intubations and $235(33 \%)<5$ preterm intubations. $65 \%$ of respondents reported never receiving neonatal intubation training. Videolaryngoscopy is used mainly for difficult airway management (27\%); only $7 \%$ prefer its use in neonatal intubation. $44 \%$ of respondents have had training in using LMAs in neonates, but only $6 \%$ have used it on a newborn infant. $70 \%$ of trainees strongly felt that a structured training programme would help them to become more confident in neonatal airway management.

Conclusion An alarmingly small number of paediatric junior doctors and ANNPs have formal neonatal intubation/LMA placement teaching, or exposure to practical experience. Developing effective strategies to train paediatric trainees in neonatal airway management is important. Videolaryngoscopy offers a powerful educational means for real-time coaching and teaching neonatal intubation.

\section{G568(P) CHOOSING THE BEST WAY TO FAIL AN UNACHIEVABLE AUDIT STANDARD: ADMISSION HYPOTHERMIA VERSUS ADMISSION HYPERTHERMIA IN THE PRETERM NEWBORN}

H Brophy, GK Tan, CW Yoxall. Neonatal Unit, Liverpool Womens Hospital, Liverpool, UK

\subsection{6/archdischild-2020-rcpch.486}

Aim The National Neonatal Audit Programme (NNAP) standard states that $90 \%$ of babies admitted before 32 weeks gestation should have a temperature at admission between $36.5^{\circ} \mathrm{C}$ to $37.5^{\circ} \mathrm{C}$.

In 2017, only 5 units achieved this standard, all of these admitted less than 25 babies. Failure may occur because of too many babies $<36.5 \mathrm{C}$ or too many babies $>37.5 \mathrm{C}$. In units with more than 50 admissions, there is an inverse correlation between the proportion $<36.5 \mathrm{C}$ and $>37.5 \mathrm{C}(\mathrm{r}=-$ $0.35, \mathrm{p}=0.0002$ ). The price of avoiding hypothermia is an increase in hyperthermia. But are both of these reasons for failure equivalent?

We aimed to compare the short term outcomes of hypothermic, normothermic and hyperthermic very low birth weight (VLBW) babies.

Method Data collected from inborn VLBW admissions between 2010 and 2017 were analysed to compare outcomes in the three groups.

Results Data were available for 1104 babies and are shown in the table 1. Outcomes in the hypothermic and hyperthermic groups were compared to the normothermic outcomes. The only statistically significant difference was the increased rate of major cranial ultrasound abnormality seen in the hyperthermic babies $(p=0.006)$.

\begin{tabular}{llll} 
Abstract G568(P) Table 1 & & & \\
\hline & $<36.5$ & 36.5 to 37.5 & $>37.5$ \\
\hline $\mathrm{n}$ & $155(14 \%)$ & $695(63 \%)$ & $254(23 \%)$ \\
Survival\% & 81.9 & 84.3 & 83.5 \\
Major cranial ultrasound abnormality\% & 8.5 & 9 & 15.5 \\
Bronchopulmonary dysplasia\% & 34.5 & 42.4 & 47 \\
Retinopathy of prematurity treated\% & 4.5 & 4 & 6.3 \\
Necrotising enterocolitis\% & 4.5 & 7.6 & 8.2 \\
\hline
\end{tabular}


Conclusion We have not seen any difference in outcome for hypothermic babies, but the hypothermia rate and the rates of the adverse outcomes were low, so we cannot exclude an effect.

We have seen an increase in the rate of major cranial ultrasound abnormality in hyperthermic babies. This has been demonstrated in previous studies.

We will continue to strive to avoid hypothermia and tolerate the resulting increase in hyperthermia rate until we know whether the association between hyperthermia and brain injury is a causal association, or just an association through the shared aetiology of infection. We are undertaking further work to investigate this.

\section{G569(P) THE CORRELATION BETWEEN EARLY GENERAL MOVEMENT ASSESSMENT AND TWO YEAR NEURODEVELOPMENTAL OUTCOME IN HIGH RISK PRETERM INFANTS}

'D Paris, ${ }^{2} \mathrm{~A}$ Allman. ${ }^{1}$ Physiotherapy, Aneurin Bevan University Hospital Board, Newport, UKi ${ }^{2}$ Neonatalolgy, Aneurin Bevan University Hospital Board, Newport, UK

\subsection{6/archdischild-2020-rcpch.487}

Aims The Prechtl General Movement Assessment (GMA) is a reliable tool for identifying babies at risk of neuromotor deficit. We sought to compare our GMA results with standardised Bayley's III neurodevelopmental outcomes for a population of high risk babies at a corrected age of 2 years.

Methods High risk premature Infants born during 2016 who received their neonatal intensive care in a level 3 NICU were retrieved from neonatal databases. Those infants who had GMA performed were extracted and the GMA results were compared with the results of 2 year standardised neurodevelopmental assessments.

Results In 2016, 32 babies born between 23 and 32 weeks gestation had GMA performed between 10 to 15 weeks of age. Most infants had 2 assessments. Their birth weights ranged from $570 \mathrm{~g}$ to 1850 g. 2 babies were lost to further follow up. 30 were invited for Bayley's III neurodevelopmental assessment at a corrected age of 2 years and of these 3 are still awaiting assessment. Of the 27 assessed, 22 $(82 \%)$ have a normal 2 year outcome and $21(95 \%)$ of the 22 had normal GMA. One had equivocal GMA. 2(7\%) of the 27 babies had unequivocal absent fidgety movements on GMA and both of these infants have severe or moderate delay across all Bayley's domains. 1(4\%) infant had equivocally absent fidgety movements and did not attend their Bayley assessment but have documented motor delay in standard clinic assessment. 2(7\%) infants had moderate cognitive delay on Bayley's testing, but normal motor and speech development and both of these infants had a normal GMA.

Conclusion Our study demonstrates a high level of correlation between abnormal GMA and disability as assessed by standardised methods at 2 years. This is most linked with motor dysfunction rather than cognitive. Our numbers are currently small as the GMA service is new to us, but preliminary results are encouraging. Abnormal GMA identified in the first weeks of life can be used to target those babies for enhanced intervention thus improving their final outcome.

\section{G570(P) THE EFFECT OF INTRAUTERINE GROWTH RETARDATION ON THE LUNG FUNCTION OF PREMATURELY BORN YOUNG PEOPLE}

${ }^{1} \mathrm{C}$ Harris, 'A Lunt, ${ }^{2} \mathrm{~J}$ Peacock, 'A Greenough. 'School of Life Course Sciences, King's College London, London, UKi ${ }^{2}$ Primary Care and Public Health Sciences, King's College London, London, UK

\subsection{6/archdischild-2020-rcpch.488}

Background Poor intrauterine growth has been shown to result in increased morbidity in infancy. Our aim was to examine the effect of intrauterine growth retardation on the lung function of prematurely born young people routinely exposed to antenatal steroids and postnatal surfactant.

Methods Lung function was assessed at 16-19 years of age. Forced expired volume at 1 second $\left(\mathrm{FEV}_{1}\right)$, forced vital capacity (FVC), forced expiratory flow at $75 \%\left(\mathrm{FEF}_{75}\right)$, lung volumes by plethysmography, diffusion capacity of the lungs for carbon monoxide $\left(\mathrm{D}_{\mathrm{L}} \mathrm{CO} / \mathrm{VA}\right)$ measurements were taken and converted to $\mathrm{z}$ scores based on sex and height. A birthweight $<$ the 10 th centile was considered small for gestational age (SGA) and those with greater birth weight appropriate for gestational age (AGA).

Results One hundred and fifty-eight young people were assessed, 37 were SGA:

\begin{tabular}{|c|c|c|c|}
\hline & $\begin{array}{l}\text { AGA } \\
\text { Mean (SD) } \\
\text { or } N(\%)\end{array}$ & $\begin{array}{l}\text { SGA } \\
\text { Mean (SD) } \\
\text { or } N(\%)\end{array}$ & $P$ value \\
\hline Male & $63(52)$ & $19(51)$ & 0.939 \\
\hline Gestational age (wks) & $26.8(1.50)$ & $27.2(1.20)$ & 0.085 \\
\hline Birthweight z score & $-0.14(0.66)$ & $-2.05(0.55)$ & $<0.001$ \\
\hline Postnatal steroids & $32(26)$ & $16(43)$ & 0.052 \\
\hline BPD & $60(50)$ & $25(68)$ & 0.055 \\
\hline At assessment age (yrs) & $17.4(0.84)$ & $17.5(0.73)$ & 0.888 \\
\hline Height $(\mathrm{cm})$ & $168(8.89)$ & $164(9.13)$ & 0.027 \\
\hline Weight (kg) & $65(15.7)$ & $56(15.8)$ & 0.006 \\
\hline $\mathrm{FEV}_{1}$ & $-0.87(1.27)$ & $-1.43(1.40)$ & 0.028 \\
\hline FVC & $-0.13(1.33)$ & $-0.57(1.34)$ & 0.093 \\
\hline $\mathrm{FEV}_{1}$ :FVC & $-1.06(1.19)$ & $-1.36(1.27)$ & 0.203 \\
\hline $\mathrm{FEF}_{75}$ & $-0.89(1.25)$ & $-1.39(1.27)$ & 0.044 \\
\hline $\mathrm{FRC}_{\text {pleth }}$ & $0.45(1.26)$ & $1.22(1.55)$ & 0.003 \\
\hline $\mathrm{RV}_{\text {pleth }}$ & $0.87(1.20)$ & $1.78(1.62)$ & $<0.001$ \\
\hline $\mathrm{TLC}_{\text {pleth }}$ & $0.76(1.17)$ & $1.16(1.15)$ & 0.079 \\
\hline $\mathrm{D}_{\mathrm{L}} \mathrm{CO} / \mathrm{VA}$ & $-1.98(1.12)$ & $-2.48(0.67)$ & 0.004 \\
\hline
\end{tabular}

Conclusion Intrauterine growth retardation was associated with impaired airway and alveolar function at 16-19 years.

\section{G571(P) NEONATAL HAEMATOCRIT MEASUREMENT: DIFFERENT METHODS, DIFFERENT RESULTS?}

E Tsouana, J Arumugam, P Nousiou, A Gupta. Department of Paediatrics, Basildon Hospital, Basildon, UK

\subsection{6/archdischild-2020-rcpch.489}

Aim Three different methods are widely available in neonatal units for the measurement of neonatal Haematocrit (HCT); centrifugation (spun micro-haematocrit; SHCT), automated 